\title{
Stress and Strain of The Frontal Parallel JOINTS WITH 3D PRINTED CONNECTORS
}

\author{
Seid Hajdarevic, Murco Obucina, Elmedin Mesic \& Sandra Martinovic
}
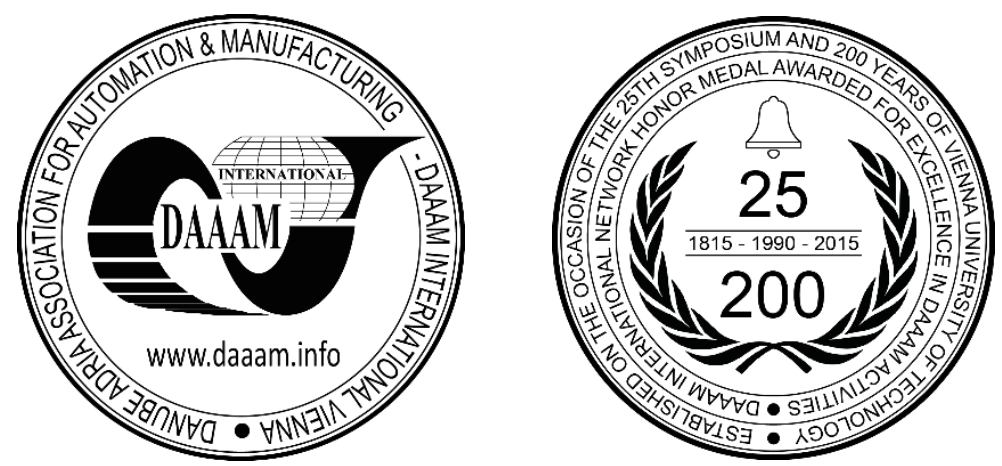

This Publication has to be referred as: Hajdarevic, S[eid]; Obucina, M[urco]; Mesic, E[lmedin] \& Martinovic, S[andra] (2018). Stress and Strain of the Frontal Parallel Joints with 3D Printed Connectors, Proceedings of the 29th DAAAM International Symposium, pp.0361-0368, B. Katalinic (Ed.), Published by DAAAM International, ISBN 9783-902734-20-4, ISSN 1726-9679, Vienna, Austria DOI: $10.2507 / 29$ th.daaam.proceedings.052

\begin{abstract}
In this paper, the stress and strain analysis of the frontal parallel joints with two different 3D printed connectors is performed. The connectors were made of PLA material and were bonded to wooden parts (spruce) with a one component polyurethane adhesive. The test was carried out to determine mechanical properties of the joints at the point of failure and proportional limit. Analytical calculations were used to determine: the effective modulus of elasticity of the joints, the normal stress of joint parts and the deflections at two directions. Numerical stress and strain analyses were performed with finite method software. The results show that the ratio between the effective modulus of elasticity of joint and the modulus of elasticity of spruce wood is 0,71 for connector without inner wall and 0,61 for connector with inner wall. The ratio between the appropriate values of the stress and deflection at the point of failure for connector with and without inner wall is approximately 0,80 and also between the appropriate values of the stress and deflection at the point of proportional limit is 0,90 . The results also indicate that the analytical and numerical calculations gave reasonable estimates of mechanical behaviour of the joints.
\end{abstract}

Keywords: wood joint; connector; 3D printed; mechanical properties; finite element method

\section{Introduction}

Appropriate strength and stiffness of joints are one of the main requirements that need to be ensured during construction process of wood structure. The analysis of the mechanical properties of the joint is more complex if the connector is used for connecting wooden parts of structure. The properties of this type of joints do not only depend on the connector geometry, but also on the connector material. A fragment of the joint in which connector is located should be analyzed as the composite material.

The studied literature has established that investigations are focused primarily on the analysis of mechanical properties of the mortise and tenon joints as well dowel joints that are the most common joints of furniture structures [1]. Tenon size (width and length) affects the bending moment capacity [2] and stiffness of joint [3]. The joint properties are most affected by tenon length [4]. The highest stiffness/strength values were estimated in mortise and tenon joints, whereas dowel joints showed the lowest stiffness/strength and deformability [5]. The same study states that the elasticity modulus of the experimental joints (substitute modulus) expressed their stiffness better than the stiffness coefficient. 
The application of the modulus of elasticity of the joint with common mechanical connectors simplifies numerical analysis of cabinet furniture construction instead of realistic modeling of elastic parts of the structure that remain in contact with one another [6]. The new technologies and new materials have been developed and applied in the furniture construction. One of the unconventional approach is the use of 3D printing technology that enables the fabrication of a complex shape of connectors from large variety of materials [7].

\section{Research objective and methodology}

The aim of this study was to investigate the applicability of 3D printed elements of a joint for connecting wood parts in furniture structure, to analysis mechanical properties of that joint obtained by different methods and to determine the effects of approach and solution of structural design. The objective was to analysis stress and strain of the frontal parallel joints with 3D printed connectors. These simple shaped and adhesive joints are commonly used to increase the length of beam elements of wood structure. The study employed experimental, analytical and numerical methods to analyze mechanical properties of joints with different shape of connectors that were subjected to bending.

Two models of connector were designed using Catia software. Shape and measures of the connector models are shown in the Fig. 1(up). All of the connector walls had a thickness of $2 \mathrm{~mm}$ and the difference in the models was in the presence of a symmetric inner wall. Six connectors without inner wall (model 1) and three connectors with inner wall (model 2) were printed on the Ultimaker 3 3D printer, Fig 1 (down). A PLA (polylactic acid) filament of 2,85 mm was used [8]. The printed layers were applied along the axis of the symmetry on two sides and along the acute angle on the other two sides of connectors. All 3D printed connectors had certain deviations from the nominal shape and dimensions.
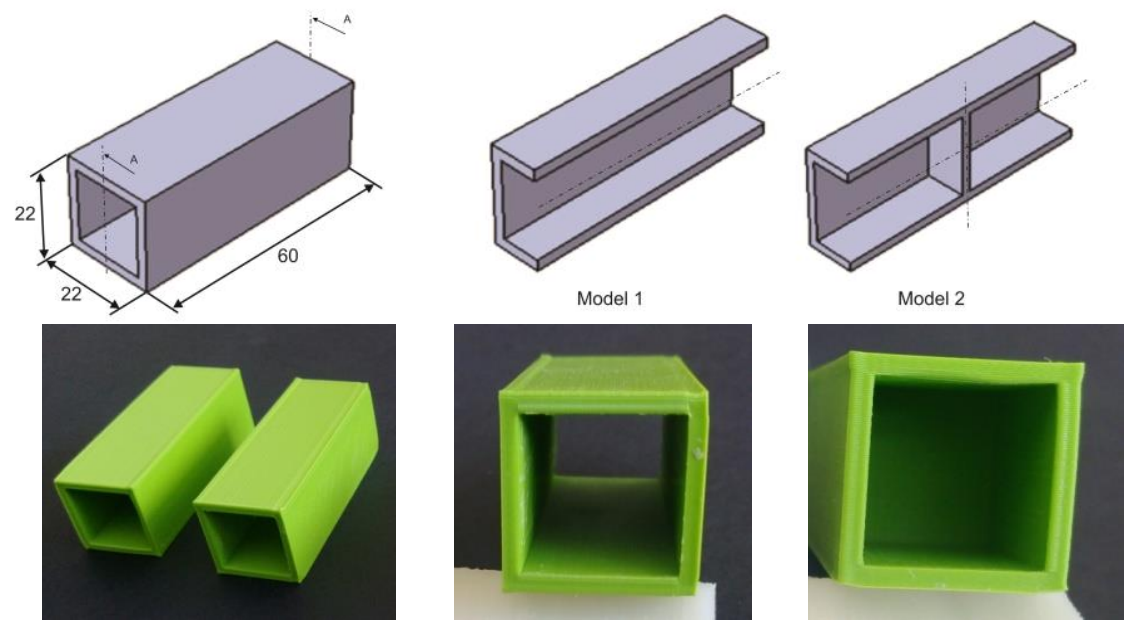

Fig. 1. 3D printed connectors without inner wall and with inner wall

The wooden parts of the frontal parallel joints were made of spruce wood (Picea abies Karst.). The average wood moisture content was $14 \%$. Connectors were bonded to wooden parts with a one component polyurethane adhesive (Kleiberit 501). The joints were left in place for four days before being tested on a universal testing machine (Zwick).

Bending test and symmetrical loading pattern was used to investigate the mechanical properties of the frontal parallel joints. Testing model setup and used apparatus are shown in Fig. 2. Length of the joint and lengths of the joint sections are: $l=280 \mathrm{~mm}, a_{1}=a_{2}=55 \mathrm{~mm}$ and $a_{3}=30 \mathrm{~mm}$ (model1) i.e. $a_{3}=29 \mathrm{~mm}$ and $a_{4}=1 \mathrm{~mm}$ (model 2 ). Diagrams for the beam in Fig. 2 show that central part of beam is without shear and it is subjected to a pure bending. The load was applied to the joint until failure occurred. The limitation of the test was inability to measure deflection at the mid-span of the beam relative to the supports. The analogue recording equipment was used to obtain load-deflection data in the direction of the force $F / 2$, taking into account local wood deformations.

The deflection, effective modulus of elasticity and normal stress were analyzed in the bending of the frontal parallel joints. The same test was applied on the ten spruce beams and deflection, modulus of elasticity of spruce wood and normal stress were analysed.

The deflections in the direction of the force at proportional limit $F_{P} / 2$ and the failure force $F / 2$ were obtained from load-deflection curve. The cross sections of joint were assumed to be constant and homogeneous, and the effective modulus of elasticity $E_{e f f}$ was calculated:

$$
E_{e f f}=\frac{\left(F_{P} / 2\right)}{6} \frac{l^{3}}{f_{P} I_{x}}\left(\frac{a_{1}}{l}\right)^{2}\left(3-4 \frac{a_{1}}{l}\right)
$$


where $F_{P}$ is the force at proportional limit, $f_{P}$ is deflection at proportional limit in the direction of the force $F_{P} / 2, I_{x}$ is moment of inertia of wooden parts of joint. The modulus of elasticity of spruce wood was obtained by the same equation.
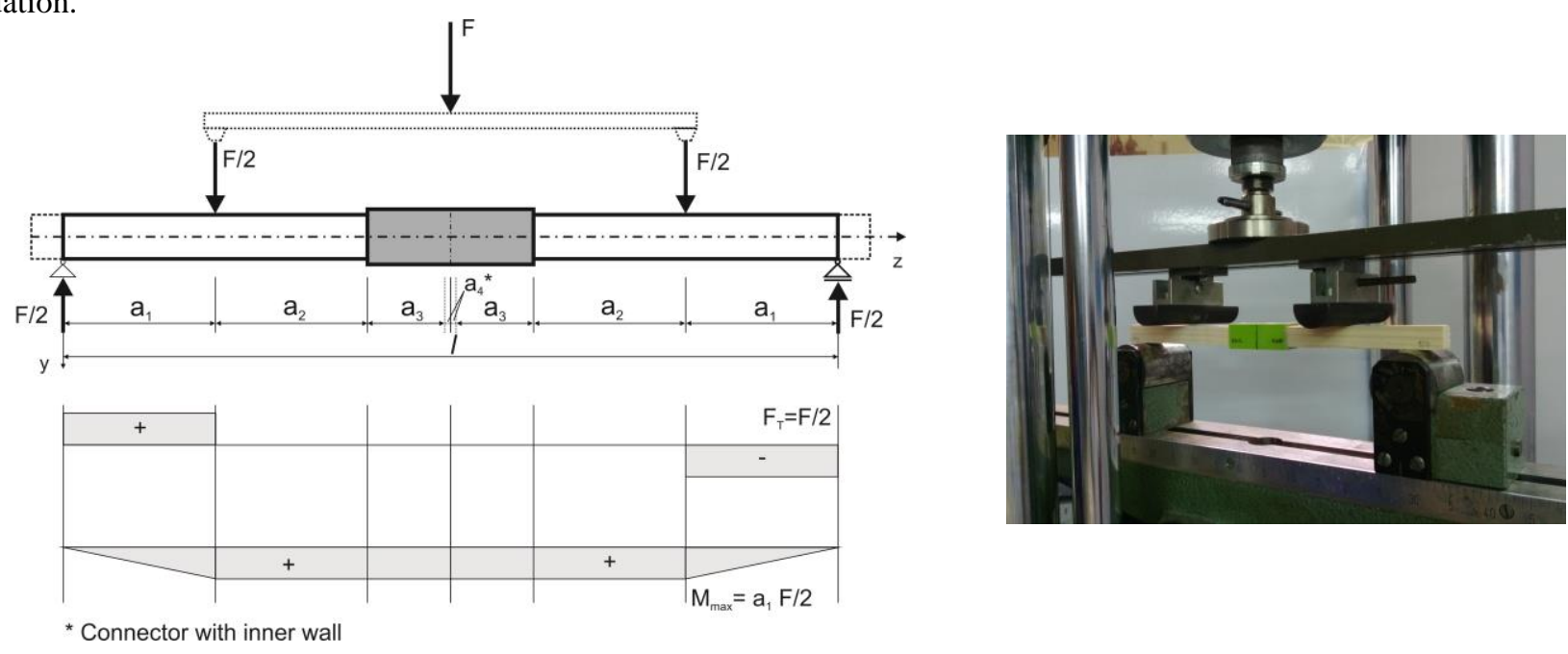

Fig. 2. Bending test of the frontal parallel joints

The normal stress was calculated for the cross sections in the central part of beam that had been subjected to a pure bending, Fig. 3. The joint lengths $a_{3}$ are composite parts of the beam i.e. the cross section of this joint parts are made of wood and PLA. The normal stress of composite part was obtained by the transformed cross section method. The equation has the general form:

$$
\sigma=n \frac{M_{x} y}{I_{T}}
$$

where $n=E_{P L A} / E_{\text {wood }}, E_{P L A}$ is modulus elasticity of PLA, $E_{\text {wood }}$ is modulus elasticity of spruce in longitudinaly direction, $M_{x}$ is bending moment, $y$ is distance from neutral axis and $I_{T}$ is moment of inertia of the transformed cross section. The equation for the moment of inertia of the transformed cross section is:

$$
I_{T}=\frac{n B H^{3}}{12}-\frac{n b h^{3}}{12}+\frac{b h^{3}}{12}=\frac{n B H^{3}}{12}+\frac{b h^{3}}{12}(1-n)
$$

where $b, B, h$ and $H$ are lengths at the composite cross section, Fig 3.
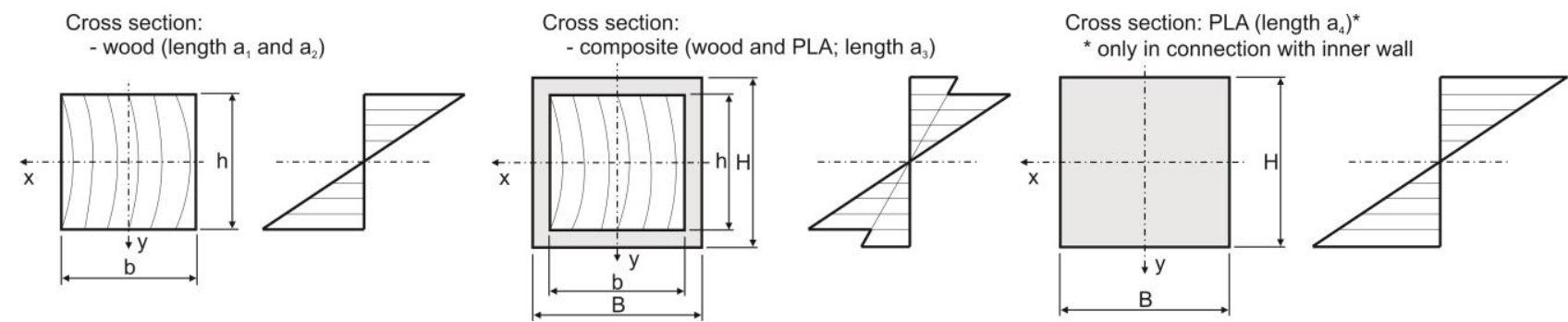

Fig. 3. Cross sections of the joint and diagrams of the normal stress

Deflection $f$ of the loaded frontal parallel joints was calculated by principle of virtual work:

$$
f=\sum_{i=1}^{n} \int_{a_{i}} \frac{M_{x} \overline{M_{x}}}{E I_{x}} d z
$$

where $M_{x}$ is bending moment due to applied external forces, $\overline{M_{x}}$ is bending moment due to unit load applied in the direction of required displacement and $E I_{x}$ is flexural rigidity of joint part. The numerical results were obtained with a numerical method based on the finite element and carried out with a linear model for orthotropic material. Calculations were performed by using the Catia software package. 


\section{Results}

Measured and calculated values obtained by testing the joints with two models of connector are specified in Table 1 . The ratio between average value of the failure force obtained for connector with and without inner wall is 0,90 . The same value is also obtained for force at proportional limit. In the joints without inner PLA wall, failure occurred, as well spruce beams, in the zone of applied force (wood) only, Fig. 4.(up and down). In the case of connectors with inner wall, jonits failed with PLA material line fracture, Fig 4.(middle). The differences between average values of the bending moment for the force at proportional limit and deflection in the direction of the force at proportional limit for connector with and without inner wall are small in contrast to the obtained values for failure force.

\begin{tabular}{|c|c|c|c|c|c|c|c|c|c|c|c|c|}
\hline \multicolumn{13}{|c|}{ Joint: PLA connector without inner wall (Model 1) } \\
\hline \multirow{2}{*}{ No. } & \multicolumn{4}{|c|}{ Dimension, $\mathrm{mm}$} & \multirow{2}{*}{$F_{\max }$} & \multirow{2}{*}{$\begin{array}{l}F_{P} \\
\mathrm{~N}\end{array}$} & \multirow{2}{*}{$F_{P} / F_{\max }$} & \multirow{2}{*}{$\begin{array}{c}f_{\max } \\
\mathrm{mm}\end{array}$} & \multirow{2}{*}{$\begin{array}{c}f_{P} \\
\mathrm{~mm}\end{array}$} & \multirow{2}{*}{$\begin{array}{c}M_{\max } \\
\mathrm{Nm}\end{array}$} & \multirow{2}{*}{$\begin{array}{l}M_{P} \\
\mathrm{Nm}\end{array}$} & \multirow{2}{*}{$\begin{array}{l}E_{\text {eff }} \\
\text { GPa }\end{array}$} \\
\hline & $b$ & $h$ & $B$ & $H$ & & & & & & & & \\
\hline 1 & 17,33 & 17,32 & 22,21 & 22,21 & 1922,76 & 1275,30 & 0,66 & 10 & 3,5 & 52,88 & 35,07 & 7,59 \\
\hline 2 & 17,55 & 17,43 & 21,19 & 22,19 & 1805,04 & 1324,35 & 0,73 & 8 & 4,5 & 49,64 & 36,42 & 5,94 \\
\hline 3 & 17,48 & 17,32 & 22,18 & 22,18 & 1922,76 & 1255,68 & 0,65 & 14 & 4,0 & 52,88 & 34,53 & 6,48 \\
\hline 4 & 17,32 & 17,41 & 22,13 & 22,13 & 1775,61 & 1216,44 & 0,69 & 12,5 & 5,0 & 48,83 & 33,45 & 4,99 \\
\hline 5 & 17,32 & 17,08 & 22,28 & 22,28 & 1471,50 & 1088,91 & 0,74 & 7,0 & 4,0 & 40,47 & 29,95 & 5,92 \\
\hline 6 & 17,35 & 17,19 & 22,90 & 22,9 & 1579,41 & 1118,34 & 0,71 & 11,5 & 4,5 & 43,43 & 30,75 & 5,29 \\
\hline $\bar{X}$ & 17,39 & 17,29 & 22,15 & 22,32 & 1746,18 & 1213,17 & 0,70 & 10,5 & 4,25 & 48,02 & 33,36 & 6,03 \\
\hline$\sigma$ & 0,10 & 0,13 & 0,55 & 0,29 & 184,37 & 92,17 & & 2,68 & 0,52 & 5,07 & 2,53 & 0,93 \\
\hline \multicolumn{13}{|c|}{ Joint: PLA connector with inner wall (model 2$)$} \\
\hline \multirow{2}{*}{ No. } & \multicolumn{4}{|c|}{ Dimension, $\mathrm{mm}$} & \multirow{2}{*}{$\begin{array}{c}F_{\max } \\
\mathrm{N}\end{array}$} & \multirow{2}{*}{$\begin{array}{l}F_{P} \\
\mathrm{~N}\end{array}$} & \multirow{2}{*}{$F_{P} / F_{\max }$} & \multirow{2}{*}{$\begin{array}{c}f_{\max } \\
\mathrm{mm}\end{array}$} & \multirow{2}{*}{$\begin{array}{c}f_{P} \\
\mathrm{~mm}\end{array}$} & \multirow{2}{*}{$\begin{array}{c}M_{\max } \\
\mathrm{Nm}\end{array}$} & \multirow{2}{*}{$\begin{array}{l}M_{P} \\
\mathrm{Nm}\end{array}$} & \multirow{2}{*}{$\begin{array}{l}E_{e f f} \\
\text { GPa }\end{array}$} \\
\hline & $b$ & $h$ & $B$ & $H$ & & & & & & & & \\
\hline 1 & 17,05 & 17,28 & 22,22 & 22,22 & 1608,84 & 1069,29 & 0,66 & 8,5 & 3,5 & 44,24 & 29,41 & 6,51 \\
\hline 2 & 17,36 & & & & 1422,45 & 1079,10 & & 7,5 & 4,5 & & 29,68 & 4,92 \\
\hline 3 & 17,11 & 17,36 & 22,30 & 22,30 & 1255,68 & 1128,15 & 0,90 & 6,5 & 5,0 & 34,53 & 31,02 & 4,73 \\
\hline $\bar{X}$ & 17,17 & 17,35 & 22,27 & 22,27 & 1428,99 & 1092,18 & 0,77 & 7,5 & 4,33 & 39,30 & 30,03 & 5,39 \\
\hline$\sigma$ & 0,16 & 0,06 & 0,04 & 0,04 & 176,67 & 31,53 & & 1,00 & 0,76 & 4,86 & 0,87 & 0,98 \\
\hline
\end{tabular}

Table 1. Measured and calculated values obtained by testing joints with two models of connector
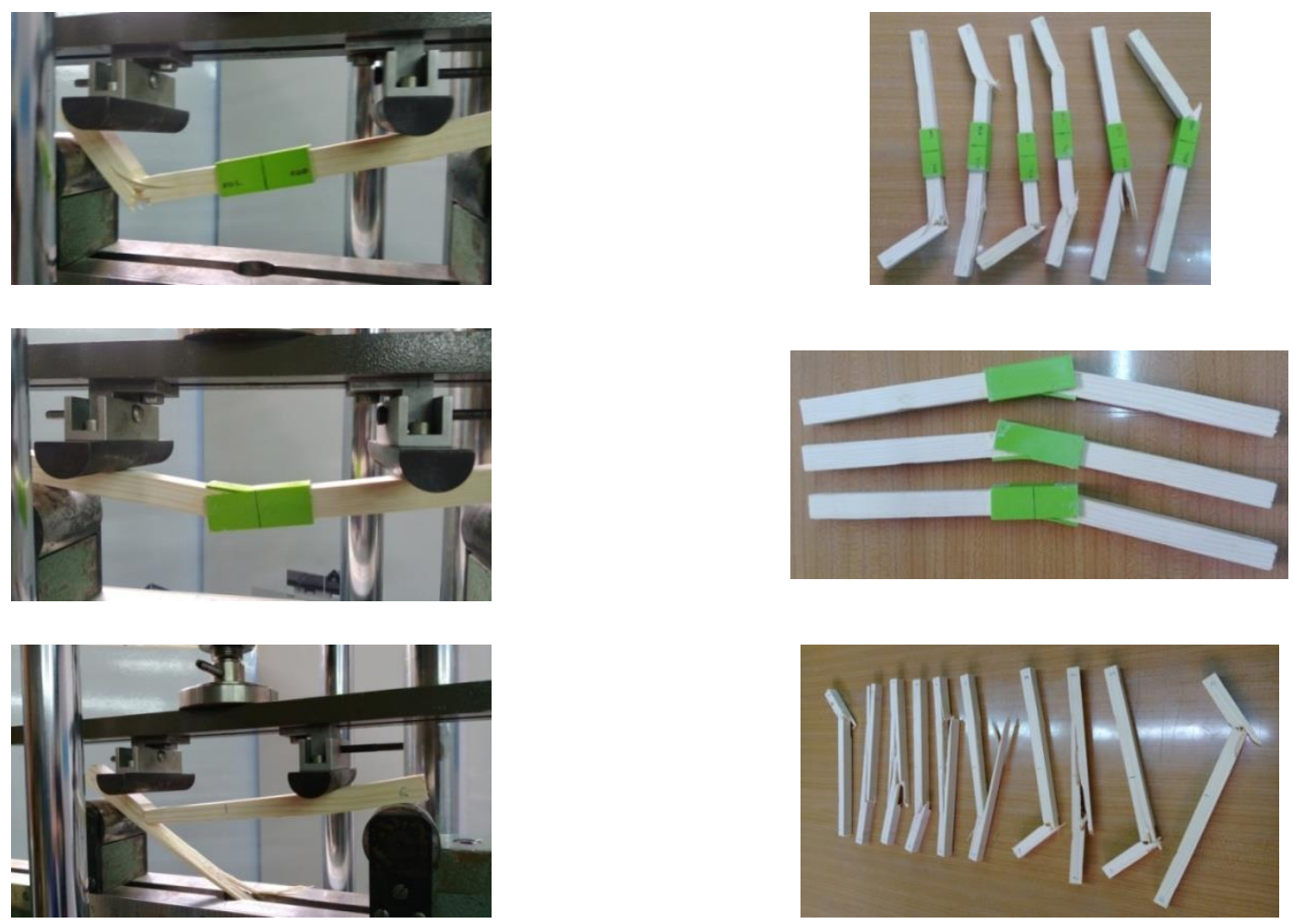

Fig. 4. Failure: connectors without inner wall (up), connectors with inner wall (middle) and spruce beams (down) 
The effective modulus of elasticity $E_{\text {eff }}$ for the joints with two models of connector and the modulus of elasticity of spruce wood $E_{\text {wood }}$ obtained by (1) are specified in Table 1 and 2. The ratio between average value of $E_{\text {eff }}$ for connector with and without inner wall is 0,89 and between average value $E_{\text {eff }}$ and $E_{\text {wood }} 0,71$ for connector without inner wall and 0,61 for connector with inner wall.

\begin{tabular}{|c|c|c|c|c|c|c|c|c|c|c|c|c|c|}
\hline \multicolumn{14}{|c|}{ Spruce beam (average $\mathrm{w}=13,56 \%$ ) } \\
\hline \multirow[t]{2}{*}{ No. } & \multicolumn{2}{|c|}{$\begin{array}{c}\text { Dimension, } \\
\mathrm{mm}\end{array}$} & \multirow{2}{*}{$F_{\max }$} & \multirow{2}{*}{$\begin{array}{l}F_{P} \\
\mathrm{~N}\end{array}$} & \multirow{2}{*}{$\begin{array}{l}F_{p} \\
/ F_{\max }\end{array}$} & \multirow{2}{*}{$\begin{array}{c}f_{\max } \\
\mathrm{mm}\end{array}$} & \multirow{2}{*}{$\begin{array}{c}f_{P} \\
\mathrm{~mm}\end{array}$} & \multirow{2}{*}{$\begin{array}{c}M_{\max } \\
\mathrm{Nm}\end{array}$} & \multirow{2}{*}{$\begin{array}{c}M_{P} \\
\mathrm{Nm}\end{array}$} & \multirow{2}{*}{$\begin{array}{c}I_{x} \\
\mathrm{~mm}^{4}\end{array}$} & \multirow{2}{*}{$\begin{array}{c}E_{\text {wood }} \\
\text { GPa }\end{array}$} & \multirow{2}{*}{$\begin{array}{l}\sigma_{\max } \\
\mathrm{MPa}\end{array}$} & \multirow{2}{*}{$\begin{array}{c}\sigma_{P} \\
\mathrm{MPa}\end{array}$} \\
\hline & $b$ & $h$ & & & & & & & & & & & \\
\hline 1 & 18,42 & 18,42 & 3168,63 & 2207,25 & 0,70 & 10,0 & 4,0 & 87,14 & 60,70 & 9593,50 & 8,99 & 83,65 & 58,27 \\
\hline 2 & 18,45 & 18,45 & 3276,54 & 2060,10 & 0,63 & 12,5 & 3,3 & 90,10 & 56,65 & 9656,16 & 10,10 & 86,08 & 54,12 \\
\hline 3 & 19,39 & 18,47 & 3325,59 & 1912,95 & 0,58 & 13,0 & 3,2 & 91,45 & 52,61 & 10181,16 & 9,18 & 82,95 & 47,72 \\
\hline 4 & 18,46 & 18,51 & 2530,98 & 1863,90 & 0,74 & 7,5 & 3,8 & 69,60 & 51,26 & 9755,95 & 7,86 & 66,03 & 48,63 \\
\hline 5 & 18,43 & 18,28 & 3021,48 & 1962,00 & 0,65 & 8,5 & 3,5 & 83,09 & 53,96 & 9381,51 & 9,34 & 80,95 & 52,57 \\
\hline$\frac{5}{6}$ & $\frac{18,43}{18,34}$ & 18,35 & 3355,02 & 2020,86 & 0,60 & 8,5 & $\frac{3,6}{3,6}$ & 92,26 & 55,57 & 9443,35 & 9,29 & 89,64 & 53,99 \\
\hline 7 & 18,45 & 18,45 & 3217,68 & 1932,57 & 0,60 & 10,5 & 3,5 & 88,49 & 53,15 & 9656,16 & 8,94 & 84,54 & 50,77 \\
\hline 8 & 18,47 & 18,53 & 2992,05 & 2011,05 & 0,67 & 11,5 & 4,0 & 82,28 & 55,30 & 9792,91 & 8,02 & 77,85 & 52,32 \\
\hline 9 & 18,50 & 18,51 & 3050,91 & 1569,60 & 0,51 & 9,5 & 3,0 & 83,90 & 43,16 & 9777,09 & 8,36 & 79,42 & 40,86 \\
\hline 10 & 18,39 & 18,44 & 3129,39 & 1814,85 & 0,58 & 10,0 & 3,5 & 86,06 & 49,91 & 9609,11 & 8,43 & 82,57 & 47,89 \\
\hline $\bar{X}$ & 18,53 & 18,44 & 3106,83 & 1935,51 & 0,63 & 10,15 & 3,54 & 85,44 & 53,23 & 9684,69 & 8,85 & 81,37 & 50,71 \\
\hline$\sigma$ & 0,31 & 0,08 & 238,06 & 169,03 & & 1,78 & 0,33 & 6,55 & 4,65 & 220,51 & 0,68 & 6,34 & 4,76 \\
\hline
\end{tabular}

Table 2. Measured and calculated values obtained by testing spruce beams

The obtained modulus of elasticity of spruce wood $E_{\text {wood }}$ is less than the literature values of modulus of elasticity under bending (10 - $12 \mathrm{GPa}$ ) [9]. The average value of maximum stress of spruce wood is well matched with modulus of rupture under bending (71MPa). The ratio between average values of $\sigma_{P}$ and $\sigma_{\max }$ is 0,62 . The values of the normal stress, calculated for the cross sections of the joint and diagrams shown in Fig.3, are specified in Table 3. The normal stress of composite part was obtained by (2) and (3) and for $E_{P L A}=3,5 \mathrm{GPa}[8]$ and $E_{\text {wood }}=8,85 \mathrm{GPa}$ (average value of modulus of elasticity of spruce wood, Tab. 2). The average values of maximum stress as well average values of stress at proportional limit of joints with connector with inner wall are less than values for connector without inner wall. The ratio between the appropriate average values of $\sigma_{\max }$ for connector with and without inner wall is approximately 0,80 and also between the appropriate average values of $\sigma_{p}$ is 0,90 .

\begin{tabular}{|c|c|c|c|c|c|c|c|c|c|c|c|c|c|}
\hline \multicolumn{14}{|c|}{ Joint: PLA connector without inner wall (Model 1) } \\
\hline \multirow{5}{*}{ No. } & \multicolumn{10}{|c|}{ Cross section } & & & \\
\hline & \multicolumn{3}{|c|}{ Length $\mathrm{a}_{2}-$ wood } & \multicolumn{7}{|c|}{ Length $a_{3}$ - composite (wood and PLA) } & & & \\
\hline & \multirow{3}{*}{$\begin{array}{c}I_{x} \\
\mathrm{~mm}^{4}\end{array}$} & \multirow{2}{*}{$\begin{array}{c}\sigma_{\max } \\
\mathrm{MPa}\end{array}$} & \multirow{3}{*}{$\begin{array}{c}\sigma_{p}, \\
\mathrm{MPa} \\
/ 2 \\
\end{array}$} & \multirow{3}{*}{$\begin{array}{c}I_{T} \\
\mathrm{~mm}^{4}\end{array}$} & \multicolumn{3}{|c|}{$\sigma_{\max }, \mathrm{MPa}$} & \multicolumn{3}{|c|}{$\sigma_{p}, \mathrm{MPa}$} & & & \\
\hline & & & & & wood & PLA & PLA & wood & PLA & PLA & & & \\
\hline & & $y=h / 2$ & & & \multicolumn{2}{|c|}{$y=h / 2$} & $y=H / 2$ & \multicolumn{2}{|c|}{$y=h / 2$} & & & & \\
\hline 1 & 7503,45 & 61,03 & 40,48 & 12555,3 & 36,47 & 14,42 & 18,50 & 24,19 & 9,57 & 12,27 & & & \\
\hline 2 & 7744,40 & 55,86 & 40,98 & 12312,03 & 35,14 & 13,90 & 17,69 & 25,78 & 10,20 & 12,98 & & & \\
\hline 3 & 7568,40 & 60,50 & 39,51 & 12551,33 & 36,48 & 14,43 & 18,48 & 23,83 & 9,42 & 12,07 & & & \\
\hline 4 & 7616,63 & 55,81 & 38,23 & 12508,81 & 33,98 & 13,44 & 17,08 & 23,28 & 9,21 & 11,70 & & & \\
\hline 5 & 7191,68 & 48,05 & 35,56 & 12468,41 & 27,72 & 10,96 & 14,30 & 20,51 & 8,11 & 10,58 & & & \\
\hline 6 & 7344,22 & 50,83 & 35,99 & 13503,01 & 27,65 & 10,93 & 14,57 & 19,58 & 7,74 & 10,31 & & & \\
\hline$\overline{\bar{X}}$ & $\overline{74494,80}$ & $\overline{55,35}$ & 38,46 & 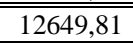 & 32,91 & 13,01 & 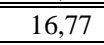 & 22,86 & $9,9,04$ & 11,65 & & & \\
\hline$\sigma$ & 198,59 & 5,16 & 2,28 & 427,42 & 4,15 & 1,64 & 1,89 & 2,35 & 0,93 & 1,03 & & & \\
\hline \multicolumn{14}{|c|}{ Joint: PLA connector with inner wall (Model 2) } \\
\hline \multirow{5}{*}{ No. } & \multicolumn{13}{|c|}{ Cross section } \\
\hline & \multicolumn{3}{|c|}{ Length $\mathrm{a}_{2}-$ wood } & \multicolumn{7}{|c|}{ Length $a_{3}$ - composite (wood and PLA) } & \multicolumn{3}{|c|}{ Length $\mathrm{a}_{4}$ - PLA } \\
\hline & \multirow{3}{*}{$\begin{array}{c}I_{x} \\
\mathrm{~mm}^{4}\end{array}$} & $\sigma_{\max }$ & $\sigma_{p}$ & \multirow{3}{*}{$\begin{array}{c}I_{T} \\
\mathrm{~mm}^{4}\end{array}$} & \multicolumn{3}{|c|}{$\sigma_{\max }, \mathrm{MPa}$} & \multicolumn{3}{|c|}{$\sigma_{p}, \mathrm{MPa}$} & \multirow{3}{*}{$\begin{array}{c}I_{x} \\
\mathrm{~mm}^{4}\end{array}$} & $\sigma_{\max }$ & $\sigma_{g p}$ \\
\hline & & $\mathrm{MPa}$ & $\mathrm{MPa}$ & & wood & PLA & PLA & wood & PLA & PLA & & MPa & $\mathrm{MPa}$ \\
\hline & & \multicolumn{2}{|c|}{$y=h / 2$} & & \multicolumn{2}{|c|}{$y=h / 2$} & $y=H / 2$ & \multicolumn{2}{|c|}{$y=h / 2$} & $y=H / 2$ & & \multicolumn{2}{|c|}{$y=H / 2$} \\
\hline 1 & 7331,19 & 50,51 & 33,57 & 12465,62 & 30,67 & 12,13 & 15,59 & 20,38 & 8,06 & 10,36 & 20313,98 & 24,20 & 16,08 \\
\hline 2 & 7621,07 & 45,52 & 34,53 & 12742,58 & 26,71 & 10,56 & 13,53 & 20,26 & 8,01 & 10,26 & 20571,17 & 21,19 & 16,08 \\
\hline 3 & 7459,64 & 40,09 & 36,02 & 12659,60 & 23,68 & 9,36 & 12,03 & 21,27 & 8,41 & 10,81 & 20608,11 & 18,68 & 16,79 \\
\hline$\overline{\bar{X}}$ & 7470,63 & 45,37 & 34,71 & 12622,60 & 27,02 & 10,68 & 13,72 & 20,64 & 8,16 & 10,48 & 20497,75 & 21,36 & 16,32 \\
\hline$\sigma$ & 145,26 & 5,21 & 1,24 & 142,14 & 3,50 & 1,39 & 1,79 & 0,55 & 0,22 & 0,29 & 160,22 & 2,76 & 0,41 \\
\hline
\end{tabular}

Table 3. The normal stress calculated for the cross sections in the central part of joints 
The ratio between the average values of $\sigma_{\max }$ for spruce wood and connector without inner wall in the zone of length $a_{2}$ is 0,68 and also between $\sigma_{\max }$ of spruce wood and connector with inner wall in the zone of length $a_{2}$ is 0,56 . The average value of maximum stress for connector without inner wall is higher than compression strength of spruce $(45 \mathrm{MPa})$ in zone of length $\mathrm{a}_{2}$. The maximum values of stress in the PLA material occured at the inner wall in zone of length $a_{4}$ (connector with inner wall). The average value of maximum stress in zone of length $\mathrm{a}_{4}$ is higher than compression strength of PLA (17,9 MPa).

The deflection values, calculated (4) for the direction of the force and at the half of length as well both models of the connectors, are specified in Table 4. Deflection at the half length of joins has a higher value than deflection in direction of the force as well in the case of connection without inner wall in relation to connection with wall. The ratio between the appropriate average values of $f_{\max }$ for connector with and without inner wall is approximately 0,82 and also between the appropriate average values of $f_{P}$ is 0,90 .

The calculate values of displacement in direction of the force are remarkably lower than the displacements obtained by test. The ratio between calculated and experimental value of the $f_{P}$ (linear elasticity) is approximately 0,55 for both models.

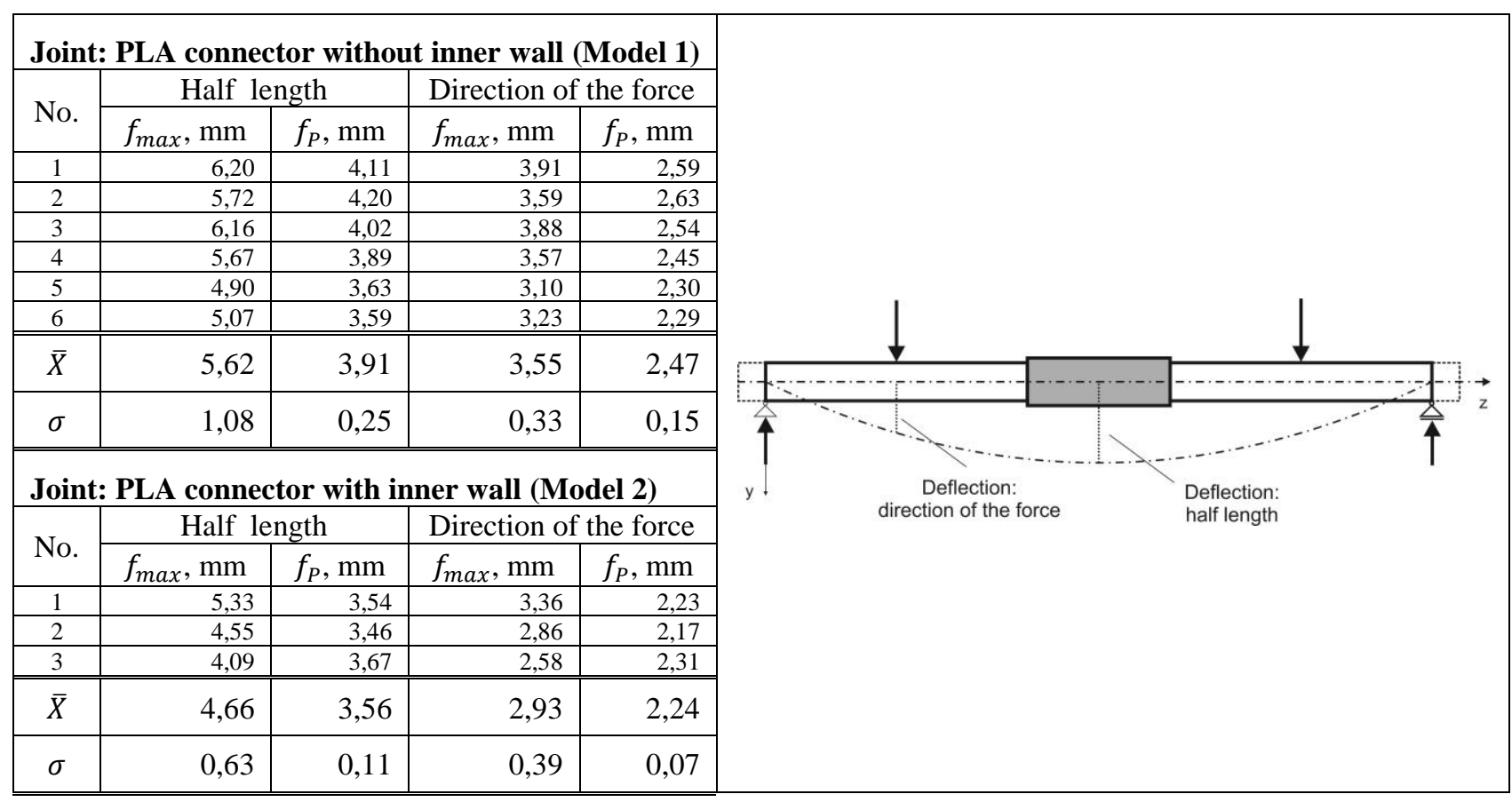

Table 4. Deflections calculated for the direction of the force and at the half of length

Numerical calculation was carried out for average values of joint dimensions and the forces at proportional limit. The glue bond is neglected. The used elastic properties for spruce wood are presented in Tab. 5 [9].

\begin{tabular}{|c|c|c|c|c|c|c|c|c|c|c|c|}
\hline \multicolumn{1}{|c|}{ Modulus of elasticity, MPa } & \multicolumn{1}{|c|}{ Rigidity modulus, MPa } & \multicolumn{1}{c|}{ Poisson's ratio } \\
\hline$E_{L}$ & $E_{R}$ & $E_{T}$ & $G_{L R}$ & $G_{L T}$ & $G_{R T}$ & $v_{L R}$ & $v_{L T}$ & $v_{R T}$ & $v_{T R}$ & $v_{R L}$ & $v_{T L}$ \\
\hline $12048^{*}$ & 830 & 420 & 623 & 744 & 42 & 0,41 & 0,554 & 0,599 & 0,31 & 0,055 & 0,035 \\
\hline
\end{tabular}

Table 5. Elastic properties of spruce wood, $\mathrm{w}=12 \%$ [9]

The numerical results of the normal stress $\sigma_{z}$ and deflection for the both models of the connectors are shown in Fig. 5. The normal stress and deflection distribution along the joint and the joint cross section coincides with analytical calculation. The numerical values of normal stress are good match with analytical results.

Differences between deflections obtained by analytical and numerical calculation are higher i.e. the analytical joint models have a higher rigidity. 

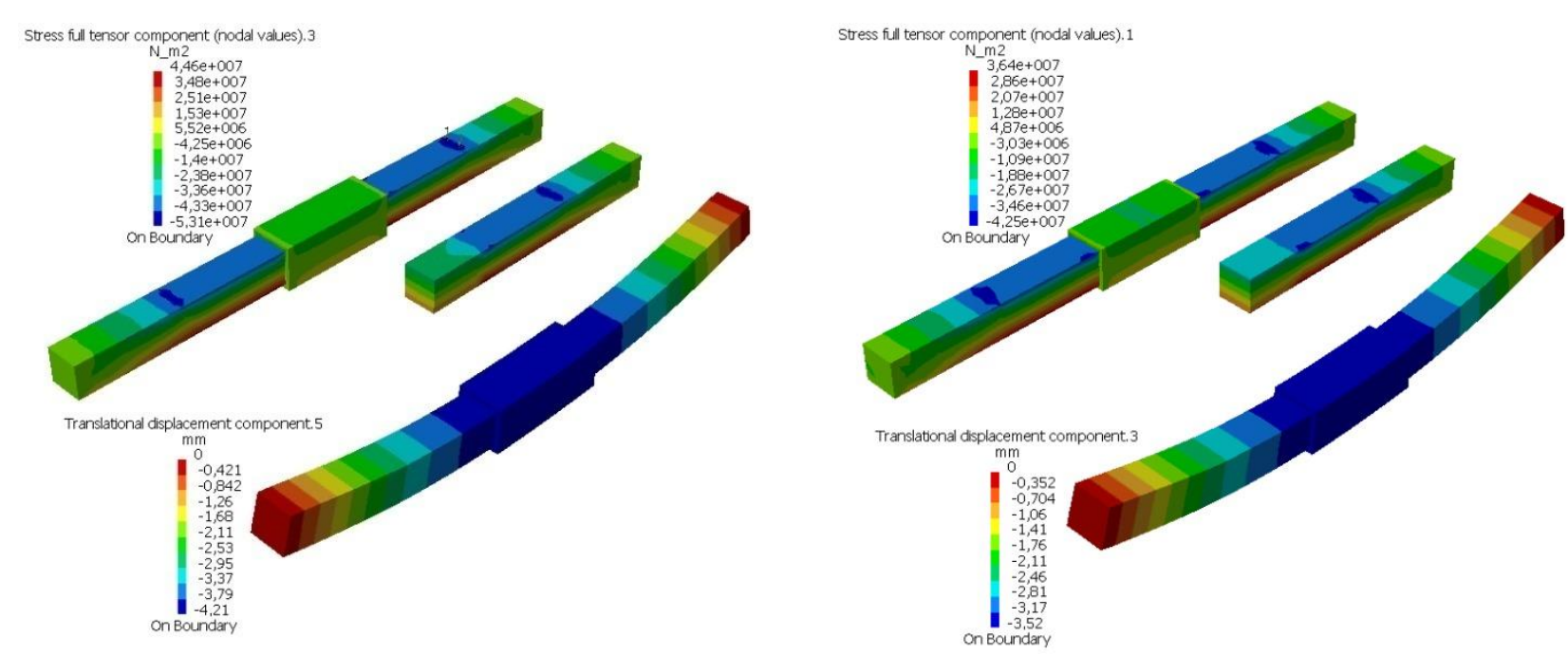

Fig. 5. Numerical results of stress $\sigma_{z}$ and deflection: connectors without inner wall (left), connectors with inner wall (right)

\section{Conclusion}

This study investigated the applicability of 3D printed elements for connecting wood parts in furniture structure. The analysis of the mechanical properties of the frontal parallel joints with two models (with and without inner wall) of 3D printed connectors was performed. The forces and deflection at the points of failure of the joints and at the proportional limit points were determined by bending test. The effective modulus of elasticity of the joints, the normal stress at the cross section of joint parts and the deflections at direction of the force and at the half of the joints length were calculated. The stress and strain states of loaded joints were determinate by numerical method.

The results show that the values of normal stress at the points of failure of the joints and at the proportional limit of frontal parallel joints with connectors were remarkably lower than the normal stress of clear spruce wood beam. The failures of joint without inner wall and clear spruce wood beam occurred in the zone of applied force while the fractures of the joints with inner wall occurred in the PLA material of the connectors. The values of the effective modulus of elasticity of joint were lower than the modulus of elasticity of spruce wood and the both modulus are less than expected due the local deformations of the wood that appeared in direction of the force.

For both models of the connectors, the calculate deflections in direction of the force did not match with deflection obtained by test. The local deformations of the wood that appeared in direction of the force, the glue as well the shape and dimension deviations of the connectors and wooden parts of joints influenced the differences between the calculated deflection and deflection obtained by the test. The good matching between the analytical and numerical results also indicates that the applied calculations gave reasonable estimates of mechanical behaviour of the joints, particularly in the elastic rang (up to proportional limit).

The structural differences (models without and with the inner wall) and material of the 3D connectors affect its mechanical properties. The ratio between the appropriate values of the stress and deflection at the point of failure for connector with and without inner wall is approximately 0,80 and also between the appropriate values of the stress and deflection at the point of proportional limit is 0,90 . Additional research needs to be done to select optimal material and optimize construction of $3 \mathrm{D}$ connectors, and also the applied procedures can be successfully used to achieve approximate data of mechanical properties of joint with any complex shape of connector.

\section{References}

[1] Kaygin, B.; Yorur, H.; Uysal, B. (2016). Simulating Strength Behaviors of Corner Joints of Wood Constructions by Using Finite Element Method. Drvna industrija 67 (2) 133-140 (2016), ISSN: 0012-6772 doi:10.5552/drind.2016.1503

[2] Kasal, A.; Smardzewski, J.; Kuşkun, T.; Erdil, Y. Z. (2016). Numerical Analyses of Various Sizes of Mortise and Tenon Furniture Joints, BioResources, Vol 11, No 3 6836-6853, ISSN: 1930-2126

[3] Hajdarević, S.; Martinović, S. (2014). Effect of Tenon Length on Flexibility of Mortise and Tenon Joint, 24th DAAAM International Symposium on Intelligent Manufacturing and Automation, 2013, Procedia Engineering 69 (2014) 678 - 685, doi: 10.1016/j.proeng.2014.03.042 
[4] Kasal, A.; Eckelman, C. A.; Haviarova, E.; Erdil, Y. Z.; Yalcin, I. (2015). Bending moment capacities of L-shaped mortise and tenon joints under compression and tension loadings, BioResources 10(4), 7009-7020, ISSN: 19302126

[5] Imirzi, H. O.; Smardzewski, J.; Dongel, N.(2015). Method for substitute modulus determination of furniture frame construction joints. Turkish Journal of Agriculture and Forestry, (2015) 39: 775-785, E-ISSN: 1303-6173, doi:10.3906/tar-1406-92

[6] Smardzewski, J.; Lewandowski , W.; Imirzi, H. O. (2014). Elasticity modulus of cabinet furniture joints. Materials and Design 60 (2014) 260-266, ISSN: 0264-1275, http://dx.doi.org/10.1016/j.matdes.2014.03.066

[7] Gress, D. R.; Kalafsky, V. R. (2015). Geographies of production in 3D: Theoretical and research implications stemming from additive manufacturing. Geoforum, 60 (2015), 43-52, ISSN: 0016-7185, doi: 10.1016/j.geoforum.2015.01.003

[8] S. Farah, et al., Physical and mechanical properties of PLA, and their functions in widespread applications - A comprehensive review, Adv. Drug Deliv. Rev. (2016), http://dx.doi.org/10.1016/j.addr.2016.06.012

[9] Niemz, P. (2005). Physik des Holzes. Education Material, http://doi.org/10.3929/ethz-a-004897092 